\title{
Reconceptualizing Networks through Greek-American \\ Return Migration: Constructing Identities, Negotiating the Ethnos and Mapping Diasporas - Theoretical Challenges Regarding Empirical Contributions
}

ANASTASIA CHRISTOU

A B S T R A C T

The article addresses the theoretical implications of how inclusive and exclusive spaces (belongingness and alienation) emerge when secondgeneration Greek-American return migrants relocate and settle in their ancestral homeland and draws attention to competing discourses of cultural disruption and ruptures in identification patterns. The ambivalent spaces of 'home' and 'host' interactions accentuate agency but also pose additional conceptual challenges for the redefinition of notions of self, belonging, and nation.

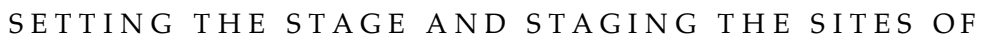

Social interaction has framed much of the discussion of ethnic and migration phenomena. It alludes to changes or stasis in the social, where the social refers to large categories of social life classifying individuals based on such categories as class, gender, ethnicity and race. In this context, projects are pursued, ambivalences clarified, values discussed, circumstances evaluated and identities formed while contested, translated, invented or reinvented, imagined, negotiated and eventually (re)constructed. What becomes important is that texts highlighting conversations with 'ourselves and others' inevitably stimulate such 
transitions and transformations. Depending on our epistemological standpoint, worldview and self-view, we remain at times confined within and at other times outside of the boundaries of class, gender, ethnicity and race. More importantly, there are times and events that result in our encountering spatio-temporal contexts, in which we are able to transcend those boundaries in search of cross-sectional identifications.

When we conceptually confine individuals and groups within the boundaries of categories, we do not always allow for the clarity of personal action to emerge and thus confine our thought only to structures. While the agency-structure schema has generated much inquiry and debate in the social sciences, I prefer not to privilege either micro-level or macrolevel approaches to the analysis of institutions and interactions. Rather I have found Faist's (1997) meso-level approach useful as it integrates productive dosages of interaction between the individual, the collectivity and the wider social space. Thinking in terms of social space instead of social structure emphasizes the fluidity of those boundaries on geographical, historical and cultural levels that delineate movement. Movement and mobility that denote notions of both home and belonging as much as notions of exile and alienation as the interplay between inclusions and exclusions are not always free of boundaries. Scholars of ethnic and migration phenomena have studied ethnic groups and their boundaries, but to what extent have we studied the fluctuation and negotiation of those boundaries over and beyond 'home-host' constructs? Has the erosion of those boundaries contributed to a more precise understanding of the multi-layered relationships that emerge and exist because of socio-cultural, historical and geographical shifts?

The title of this article points to the ways social interaction in networks of returning migrants constructs socio-cultural and ethnic ties, connectedness and cohesiveness but not necessarily always coherence. That is, they are not always idyllic spaces of interaction. They can also become spaces of exile and alienation, thus producing ambivalent identities from which the 'stranger' within emerges (Christou 2003a).

In this article I would like to focus on how and why these 'exilic' spaces can extend to the 'idyllic' space of the ancestral homeland, which is supposedly the site of the national home and the source of ethnic belongingness. To this end it is illuminating to draw upon social interaction in trying to unravel the complexities of the social construction of identities, which is in the plural to illustrate the multi-layered aspect of 
such identifications. Paying attention to social interactions and social networks in the mundane ordinariness of everyday conversations opens up new dialogues about how to conceptualize and empirically unveil the multiplicity of voices that articulate the social, the ethnic and the cultural in the national. Such explorations precipitate the problematic of social networks and return migration and serve as an alternative theoretical framework in so far as networks can be used as an analytical tool in empirical qualitative research in migration studies.

The empirical base of the research is the gathering of 40 life-stories (oral and written narratives) of second-generation Greek-Americans who made a conscious decision during the last decades to relocate from the country in which they were born (the United States) to the country of their ancestral heritage (Greece). The analysis in my research can be visualized as a schema composed of three distinct rings: networks of migration (United States), networks of return migration (Greece), and networks of the returnee/migrant. In this simple format, three basic constructions are interrelated as they interact: 'home,' the 'host,' and the 'migrant.' Home could be the United States, but it could also be Greece. For the 'host,' the same holds true. The 'migrant,' forever a traveler and a sojourner, is as much a returnee as a migrant in, between and across 'home-host' constructs. My point of departure is that migrants and returnees are connected; they establish, negotiate and produce distinct networks, which they also reconstruct, alter and reformulate as spatio-temporal contexts permeate and have an impact on those relationships. Before I present the interrelationships and networks encountered in my research, I would like to discuss the theoretical and epistemological challenges that emerged during the research process as I reflected on the ethnography itself.

\section{REFLECTING ON THE ETHNOGRAPHY}

Qualitative methods, such as participant observation, focus groups, indepth interviews and narratives, proved better suited to explore the role of agency, the meanings, insinuations and connotations that underlie the dynamics of migrant networks. Qualitative methods are much better suited than quantitative methods for addressing and further exploring meanings, processes and experiences in individuals' lives that not easily quantifiable. These methods are consistent with my epistemological framework of a social constructionism that employs both phenomenological and feminist perspectives (in my work on gender and 
migrant networks) as they provide participants with the opportunity to account for their own experiences in their own words and to account for how the social world reflects their own perceptions of that world.

After conducting a pilot study in my project, it became clear that accessing the quality of individual perceptions was necessary to illuminate constructions of nation, place, culture and identity as well as the dynamics of 'home-host' constructs in returning migrant networks. This research perspective meant that the most appropriate methodology would be a qualitatively based ethnography of return. This particular methodology was useful in unveiling the meanings and processes encoded in the act of return migration in relation to both the 'social' and 'ethnic' construction and articulation of migrant networks. While the social component reflects everyday life in a historical and political context, the ethnic reflects migrant life in a cultural and ethno-national context. In both respects all spaces of interaction are gendered, classed, ethnicized and arenas of identification (Christou 2003b, 2003c).

Migration and return migration are dynamic processes within dynamic circumstances. The migratory project is a manifestation of agency in the interactive process between actors and structures. The changing context of the return migrants' own lives provided participants with the opportunity to actively participate in all phases of the research. Beliefs about the social world at large are assumed to be constructed and altered by our dialogue and experiences with others. Individuals' accounts of their life experiences are a reflection of the society in which they reside, which is why it is imperative to listen to participants' own voices in studying return migrant networks. Life-story methods can be fruitful in revealing self and social processes. This method emphasizes the role of the individual as a storyteller whose life-story is a reflection of identity constructions and cultural reconstructions. Personal stories are not merely a means of storytelling without substance, inquiry, and intervention; rather they become the means by which identities are redefined and networks understood.

It became apparent primarily due to my positioning as an 'insideroutsider-within' that reflexivity had to be maintained throughout all stages of the research process and during the analysis, interpretation and presentation of the material. In reflexive ethnographies, the researcher's role is critical, especially in how it illuminates the culture under study. Reflexive ethnographies range along a continuum from starting research 
on the basis of one's own experience to ethnographies in which the researcher's experience is actually studied along with the other participants, to confessional tales in which the researcher's experiences of doing the study become the focus of investigation (Ellis and Bochner 2000). The idea of critical self-awareness and the oxymoronic nature of participant observation, which leads most times to the observation of the participant and hence the participation of the participant (Tedlock 1991), all blend together in the ethnographic scene of encounter, which, in turn, becomes an ethnographic dialogue of the self and other. It has been argued that because we cannot study the social world without being a part of it, all social research is a form of participant observation (Hammersley and Atkinson 1983). As Yang notes, "My fieldwork was my own life and the lives of others in which I had an active part" (1972: 63). Hence, it is important that researchers remain committed to a critically humanistic method that studies the social world from a gendered, historically situated and interactive perspective. With this kind of complex commitment in mind, we can embrace a critical, cross-cultural dialogue. Only then can we give voice to the other: that which lies within and outside the self and the text.[1]

My research project aimed precisely at questioning essentialist views in relation to ethnicity, identification and national representations. A deep dissatisfaction with previous studies that attempted to define ethnicity solely as primordial led me to consider a multiplicity of constructions and representations of nation, gender, and ethnicity as representations of individual and collective identifications. The combination of qualitative methods detailed above entailed the use of additional methods as the research progressed. Textual and discourse analysis of electronic and print texts as well as visual methods were integrated into the data collection and analysis.

One of the first challenges I faced in the fieldwork process was the use of terminology that immediately created a volatile 'power-knowledge' situation. This was a positive outcome although it may sound negative; the participants in my study could not but become aware of the underlying implications that networks held for them and the socio-cultural context of

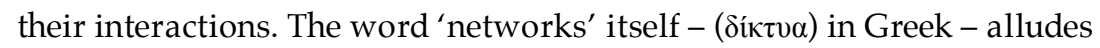
primarily to power relationships. It may point to nepotism and corruption and exclude non-members based on certain categorizations. Although I did not originally consider such implications in the analysis of my data, it 
became impossible to ignore that power, seen as productive of subjectivity or identity, figures prominently in the conceptualization of social networks. At the same time, this nexus of arguments is consistent with Pred's (1989) insistence on taking seriously "the language of everyday life," which he explains as possessing a definite geography anchored in the differing economic, social and political circumstances of different places: "Words spoken in place, Meanings made in a place, Words and meanings here, but not there" (quoted in Cloke et al. 1990: 91; my italics). My (re)conceptualization of networks as both 'social' and 'ethnic' signifiers of return constructions is a proposal to bridge not only words but worlds and meanings of both the 'here' and 'there.'

Theoretically oriented empirical studies of immigration that examine networks from a variety of frameworks and theories have blazed an energetic trajectory in the past decade and built bridges between the humanities and the social sciences. Networks have been examined and advanced as conceptual frameworks to investigate larger themes. To this end, older concepts have been analytically reshaped and new notions applied. It is neither my intention here nor is it possible to provide a thorough literature review of such developments. Rather, I will provide a sketch of the framework I developed through a critical review of major conceptual perspectives and studies.

In broad terms one can distinguish between two major approaches in theoretical readings and empirical insights: 1) societal constructions of social networks that focus on the collectivity as understood through a social prism of 'home-host' categories and constructed within the collective sense of place and identity, and 2) migrant constructions of social networks that focus on the individual as an 'active-actor' who shapes and is shaped by a 'politics of identity' within hybridized notions of belongingness (Christou 2003a). These broad distinctions integrate both structure and agency in the construction and comprehension of social networks in cases of return migration. The meso-level approach helps us appreciate how structurationist perspectives may illuminate metamigration formulations: structures are penetrated by agents as much as agents are saturated by them. Social and political fields may be used to explore how structures operate in the sense of everyday being and becoming. Thus a concrete argument can be advanced in relation to the formation of returning migrants' social networks: returnees' experiences and trajectories are highly embedded within socio-cultural constraints, 
and possibilities emerge either in opposition or in response to the local and national spaces and places of sending and receiving contexts that shape these networks. Social networks stimulate and are stimulated by national discourse. The importance of the local in understanding the translocal and the transnational cannot be emphasized enough. Methodologically such explanations must be differentiated, on the one hand, from individualist positions that attempt to explain social phenomena in terms of rational calculations made by solely self-interested individuals and on the other from theoretical explanations that view social interaction as a social exchange modeled solely on economic actions, motivated by rewards and profits. Alternatively, collective action, social norms (i.e. trust, altruism, reciprocity, obligation, moral and ideological commitment) and the cultural politics of spatial constructions are necessary to move the meso-level approach beyond the structure/agency dichotomy. This approach must take into consideration place as "an historically contingent process" and the "becoming of place as interwoven with individual biographies" (Pred quoted in Cloke et al. 1991: 117).

Portes's work on social networking is also useful. It draws on social capital - the "individual's ability to mobilize resources, be they economic tangibles or economic-related intangibles" (Portes 1995: 12; italics in original) - and focuses primarily on the economic adaptation of ethnic populations created by immigration. As the theme of this article suggests, the 'ethnic' is as important a factor as the 'social' in the construction, reproduction, persistence and functionality of networks. As important as an individual's ability to mobilize resources is, it is not devoid of spatial constraints or influences, with the spatial including politico-cultural and temporal contexts. Resources are not simply out there, unconnected from their surroundings. Although Portes instructs that "social capital is a product of embeddedness" and the ability to obtain such resources is "a property of the individual's set of relationships with others" (1995: 13), I would like to point to the importance of locating those relationships within their broader spatio-temporal context in order not to ignore the dynamics of that context.

Of vital importance but insufficiently theorized as to their emergence and wider implications are the social spaces that evolve as social networks fluctuate between the imaginings of 'home-host' relationships and the practicalities of return migration. Although the role and dynamics 
of transnationalism and transnational social spaces have been addressed in such works as Faist (2000), Pries (1999), Hannerz (1996), GlickSchiller et al. (1992), and although recent research is marked by an increased interest in the second-generation (Levitt and Waters 2002, Cordero-Guzman et al. 2001, Rumbaut and Portes 2001, Gans 1992), it is primarily limited to receiving societies and has tended not to focus on the sending societies and the trajectories of returnees. In trying to speculate about the possible future tendencies of return migration, however, we are confronted with many dilemmas, many blurred concepts and many puzzling questions. The concern that, for example, Faist raises in connection with the second-generation highlights one of the gaps in the research on second-generation return migration:

Regarding return migration, it is likely that each type of migration has a differential impact on the propensity to go back to the country of origin, depending on whether it be permanent migration, recurrent migration or temporary migration. These types of movement involve widely differing levels of commitment on the part of the mover to origin and destination.... [I]n the case of permanent migration, we would expect that ties and linkages, of both material and symbolic nature, gradually decline as time passes. In the second generation we would expect these ties to the communities and countries of origin to be less prevalent than among the first generation. Yet, it is an open question for empirical investigation whether facilitated means of transportation and exchange of information and goods could prolong the period in which strong and symbolic social ties are maintained to the country of origin. (1997: 267-268)

My findings, as discussed later in this paper, are that, at least for returnees, second-generation ties are clearly maintained and are strong indeed. The desire to transform the symbolic into something closer to the real cannot be overlooked when individuals of this generation make a conscious decision to return to their parents' country of origin. Some counter-migrate and then remigrate but still consciously construct their sense of identity and sense of place beyond their parents' imaginary. In attempting to establish as norms 1) that dual or multiple geopolitical identities are impermissible and 2) that geopolitical allegiance must be to a "land," Peter Murphy begins his analysis of nationalism with the maxim: "No one can have two countries" (1998: 369). Elsewhere I have demonstrated the danger in seeing place and identity as something static, monolithic, essential and solid (Christou 2002). Multidimensionality and multiplicity, fluidity and change are characteristics of cultural forms and vital aspects of critical geographic thinking, and certainly warrant further ethnographic attention. 


\section{NETSCAPE NETWORKING OR ESCAPING THE NETS OF \\ THE 'ALIEN' NATION \\ (REFLECTIONS ON EMPIRICAL SPACES OF \\ I N T E R A C T IO N )}

Ethnic networks have been an integral part of the Greek-American community in the diaspora. In addition to serving as socio-cultural and religious centers and assisting compatriots with the adjustment to their new surroundings, these organizations have been active in charity, humanitarian aid and scholarship funding. To this day Greek-Americans show great zeal and dedication to the causes and goals of their organizations, and a great commitment to philanthropy. Forces motivating entry into a specific club often have a geographical component - hence the creation of such clubs as the Cretans, the Arcadians, etc. Greek-American organizations are broadly divided into those that have a national agenda, volume and scope and those with regional and local ones.[2] It is widely accepted that the Church and Greek-American organizations have been instrumental in immigrant life. However, they have not been conflict-free. At times they have constituted arenas of competition and tension (Karpathakis 1994) possibly because, as research has shown, multiple attributes of ethnicity relate to the activities of these organizations and societies (Constantinou 1996). However, as Constantinou notes, "often, members of different ethnic organizations, even local societies, rise above narrow group interests and support broad ethnic causes and concerns" (2002: 113). Despite this, the future of these 'official' networks seems quite grim: they have been unable to make the transition from immigrant to American-born membership and have been less than successful in getting youth involved (Constantinou 2002).

While the role of personal contact and interaction with members of the group has been characterized as indispensable in the maintenance of ties and thus of ethnic identification (Christou 2001, Constantinou 2002), satellite technology and new technologies such as the internet and the use of electronic communication play an increasing role not only in strengthening contacts (Constantinou 2002) but most importantly in constructing new patterns of networks and shaping the content of those networks.

The term networks, as used here, thus refers not only to 'official' organized systems or activities that form a society, association or 
organization within the Greek-American community but also to the 'unofficial,' that is, to activities that do not necessarily involve membership screening, applications and fees, and may take place in private as well as public spaces. As they may not necessarily require physical contact, they could also be virtual, even anonymous communities, which either have a clear agenda of action or simply take actions from which an agenda can be deciphered. This ultimate agenda, as deciphered throughout the fieldwork research, constitutes the variables that negotiate, contest, question and construct the 'ethnic' component of the network group.

The case of a cyber-networking group, a virtual diasporic community of second-generation return migrants, accentuates the construction of the 'ethnic' component of identification as it transcends the simplistic communicative aspect of the new technologies and questions sociopolitical spaces. A prime example is the series of reactions in both 'home' and 'host' countries in response to the recent war in Iraq. From conversations I had with participants, the majority of second-generation Greek-American return migrants would seem to have "identified" with Greek mainstream political positioning and the intense anti-Americanism and anti-war sentiments in Greece. Some were appalled with some of the electronic communications they had with "Greek-Greeks" [3] in the United States who had adopted a pro-war perspective rationalized through arguments about the necessity of combating terrorism, thus identifying the war as a war against terrorism. In electronic communications with second-generation Greek-Americans permanently residing in the United States with no intention of relocating back to Greece, I found a mid-range apathy and indifference to world events but an intense concern with domestic security and personal safety on multiple levels (physical, professional etc.). In line with the theme, scope and purpose of this article, I am limiting the discussion to how this case study contributes to the conceptualization of return migrant networks. More analytical theorizations of the empirical material appear elsewhere (Christou 2003a, 2003b).

Norms of trust, obligation, and reciprocity are the crux of social networks and are established through membership in such networks (Portes 1995; Light and Gold 2000; Marger 2001). Social networks influence ethnic groups in both 'home' and 'host' contexts. Such networks may influence immigration decisions, settlement patterns, and social incorporation (Elliot 1997). They provide support systems, assistance, 
information, and psychological, if not financial, security. As my focus is on return migrant networks, I was interested in the substance behind the 'official' and 'unofficial' networks that develop during the return settlement process. The symbolic and pragmatic action plan of the 'official' organizations, ranging from national celebrations to fundraising, presents itself as a transplantation of Greek-American networking practices and practicalities whereas the existence of a hybridized, critical space created by returnee members of the second generation highlights the dynamic between the 'active-actor' (return migrant as agent) and the 'passivestructure' (constructions of national discourse in networks). A prime example of the 'unofficial' organizations, on the other hand, is the use of cyber networks that have a communicative, social and ethnic component, for which the following theoretical considerations are pertinent.

The 'actor-network theory' (ANT) (Callon 1986a, 1986b; Latour 1987, 1988; Law 1988, 1991) that has found its place in the sociology of science and technology[4] is useful with respect to cyber networks in so far as it resembles Ervin Goffman's (1969) symbolic interactionist answer that human beings have bodies but also inner lives. Social agents are never located in bodies alone; rather, an actor is a patterned network of heterogeneous relations. Hence the term, actor-network - an actor is always also a network. This poses a challenging path of inquiry between the pragmatic or imagined 'homogeneity' of ethnic groups that function also as 'ethnic' networks and the 'heterogeneity' of voices and practices shaped by a continuum of relations among the migrant-actor and the 'home-host' constructs. In this respect 'actor-network theory' approaches structures as sites of struggle, as do several other contemporary social theories, such as Elias' theory of figuration (1978), Giddens' notion of structuration (1984) and Bourdieu's concept of habitus (1989).

Attention must be also given to the assertion by social scientists and philosophers who insist that virtual networking is solely a representation of a synthetic world artificially created by technology and specifically the claim that in these groups "there is the invocation of community, but not the production of a society. There is a 'groupmind,' but not a social encounter.... This is another synthetic world, and here, too, history is frozen" (Robins 1995: 150). This poses another challenging question insofar as history can not only be frozen but constructed, negotiated and actively contested in the spatial context of networks. 
The sociality of enclaved social spaces constructed in opposition to place share similar parallels with the recent views on the sociality of the numerous 'parallel' social tribes[5] that never fully meet each other. This partly justifies the redefinitions of collective and private space in network interactions and how this is modified and adapted to the need of visibility and physical confrontation. Interaction between different actors where structures are questioned or defended no longer takes 'place' in 'authentic' surroundings. This can be meaningfully deciphered when we explore the spatio-temporal construction of public and private notions of space and interaction.

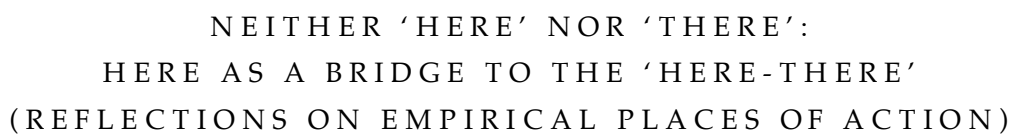

Elsewhere (Christou 2002), I have discussed the empirical findings of how, upon returning to Greece, return migrants construct their identity and sense of self in relation to place through processes and institutions which aid adjustment and settlement. Family and kinship networks as well as some formal associations provide a first layer of adjustment, but it is primarily their own experiential interactive everyday encounters with life in the ancestral homeland that shape their return journey and identification processes. Here, I would like to argue that the emergence of 'official' forms of return migrant networks constitutes reproductions of national representations. At the same time, these networks also stimulate alternate responses and a fresh critique of nationalist and xenophobic reactions. This was one of the main explanations offered by participants in the study for why they refuse to enter such groups and have as an alternative considered forming their own unofficial ones. With local associations that had a gender dimension (e.g. women only), the critique was particularly fierce: my 20-40 year-old female return migrants emphasized that "they are only interested in exchanging recipes over coffee and cake, talking about how wonderful their kids are and gossiping about others; besides they are all my mom's and my grandma's age" (a common sentiment expressed by many of the participants in my study). The reality of these women's lives goes beyond simple dichotomies; it is a reality embedded in active engagement with subjecthood, identity and social transformations (Radcliffe 1983; Christou 2003c). Theoretical spaces need to be explored, mapped, charted, and contested, especially in 
the case of individuals on the move. Critical scrutiny is necessary for spatial conceptions that illustrate positionality, displacement, territory, locality and grounding. The autonomy of the gendered self is contingent upon their individual capacity to produce meanings and to organize their activities as self-conscious expressions of daily and life practices (as spouses, professionals, parents, citizens).

Another point of departure is the generational gap that exists in the case of return networks. That is, there is a lack of organizational activity that would be suitable for people in their 20s, 30s and 40s, which appears to be the predominant age range of returnees (Christou 2003a, Appendix 1). Surrounding all these dynamics is the social, political and historical context of the homeland structure in an era of crises and conflicts. The generational gap, the construction and ambivalence of the ethnic component in networks, and the overall socio-political and historical circumstances of 'homeland' and 'hostland' contexts are important features of return migrant networks.

What we need to further explore is how these two components interact and (re)produce themselves. Return migrant networks pose challenges in understanding contemporary transformations of social relations, cultural fields, collectivities and individuals. Viewing society as a network of networks encourages focus on processes involving individuals, the material world, and symbolic elements, all of which are networked with each other. Moreover, virtual ethnography (Hine 2000) leads us to rethink traditional ways of studying networks, culture, society and migratory projects.

CHALLENGING THE FUTURE OF NETWORKS

(WORKING OUT DISCREPANCIES IN THEORY AND

$$
\text { D A T A ) }
$$

Although qualitative methodologies have been useful in my framework of research and analysis, they are not appropriate for inductive analyses. When generalizability is required, the researcher must employ quantitative research techniques and adequate sampling methods. For my material, however, quantitative methodologies were not particularly useful since the crux of the research was complex and abstract concepts related to the emergence, negotiation and construction of returning migrant networks. Such meanings and understandings are not easily or effectively 
quantified. The notions and terms that underlie networking are in themselves ambiguous and have been subject to a variety of interpretations. In any migratory project, processes, from stasis to praxis, are valuable tools that capture the multidimensionality and ongoing transformations of networks. Gaining a deeper understanding of the complexity of these processes requires a methodology that enables us to engage in-depth with the lives and experiences of others (Dwyer and Limb 2001: 1; italics in original). Hence, qualitative methodologies, which explore the feelings, understandings, experiences, plans and knowledge of others through interviews, discussions and participant observation, are increasingly used by geographers to explore the complexities of everyday life in order to gain deeper insights into the processes shaping our social worlds. These strategies confront the complexities of how lives are lived and how practicalities of everyday life are constructed through the endless journey of migration and settlement.

A (re)conceptualized framework of network theory can thus be understood on a heuristic level of analysis that considers return migrants as self-defined within their own diaspora community and beyond transnational networks that extend across national borders, within nation-states but beyond national constructs. I find myself in complete agreement with Nelson in hoping that "geographers [will] stand to make important contributions to debates about the situatedness of the subject and the doing of identity... [and] geographers... [will] think through how to spatialize and historicize the creation and recreation of identity" (1999: 348-349). I believe that a challenging starting point for a cartography of returning migrant networks could be to map how individuals and collective subjects articulate agency in relation to various discursive processes (e.g. class, race, gender and identity), to other subjects, and to layers of institutions and practices - all located concretely in time and space (both real and virtual).

At the core of the argument suggested in this article is that individual migrants as actors and collective subjectivities should be explored as dynamics in a context of interactive settings that include and do not exclude those dynamic relations. Social life is not static, but it is not completely fluid either. As Domingues suggests, "the actual possibilities given in the concrete situations in which individuals and collectivities find themselves entangled must not be neglected either" (2000: 39). This kind of awareness, which I hope to have demonstrated in this theoretical reflection on my fieldwork, can help us understand networks in a way 
that avoids the pitfalls of essentialism while unveiling new transformations.

\section{A C K N OW LEDGEMENTS}

This article draws on my DPhil thesis at the University of Sussex, which was supervised by Professor Russell King whose valuable feedback, insightful and constructive readings of my work have substantially benefited my research and writing. I am also grateful to the participants in my study, whose contributions have been instrumental in completing the research. I am forever indebted to Dr. D. Mentzeniotis for his unconditional support over the years. Finally, I am indebted to Dr. Wladimir Fischer, who carefully read an earlier draft of my article, twice, both as discussant and editor, and provided detailed feedback that I have tried to respond to and incorporate as best I could; therefore, all shortcomings are mine alone.

\section{ENDNOTES}

[1] We are then confronted with the issue of the self: Whose self? What self? Which self? This is a complex discussion that extends from the deconstructed "authentic self" to the polyvocality of the "post"-post period. For a solid presentation of these issues, see Gergen and Gergen, 2000.

[2] A thorough discussion of Greek-American associations that highlights many interesting aspects of organizational activity can be found in Constantinou 1996 and Moskos 1999.

[3] These would be individuals who have recently moved to the United States for either academic or professional reasons but also as tourists and visitors and, hence, are not necessarily seen by themselves or others as migrants or in the process of being 'Greek-Americanized.'

[4] Special thanks to Dr. D. Mentzeniotis for generously sharing his wisdom and research material on this highly complex subject. An earlier version of this paper was presented at the Conference "Conceptualisation des réseaux sociaux en migration: productions empiriques et défis théoriques," Séminaire international organise par MIGRINTER (CNRS / Université de Poitiers, MSHS Poitiers - 26 \& 27 mai 2003), with the title, "Idyllic and exilic spaces of interaction: constructing the social along the ethnic in return migrant networks at the ancestral homeland," and a revised version was presented at the NetCultureScience Conference organized by the Austrian Science and Research Liaison Office Budapest and Kakanien Revisited for Central European Studies in Budapest, 1013 December, 2003.

[5] The time of the postmodern is the time of the neo-tribalism according to French sociologist Maffesoli (Le Temps des Tribus, 1988; The Time of the Tribes, 1996). 


\section{WORKS CITED}

Brettell, C.B. and Hollifield, J.F. (eds.) (2000) Migration Theory: Talking Across Disciplines, New York: Routledge.

Bourdieu, P. (1989) Distinction: A Social Critique of the Judgment of Taste, London: Routledge.

Callon, M. (1986a) "The Sociology of an Actor Network: The Case of the Electric Vehicle," in Callon, M. et al. (eds.) Mapping the Dynamics of Science and Technology: Sociology of Science in the Real World, London: Macmillan, pp. 19-34.

. (1986b) "Some Elements of a Sociology of Translation: Domestication of the Scallops and the Fisherman of St Brieuc Bay," in Law, J. (ed.) Power, Action and Belief: A New Sociology of Knowledge?, London: Routledge \& Kegan Paul, pp. 196233.

Castles, S. (1993) "Migrations and Minorities in Europe. Perspectives for the 1990s: Eleven Hypotheses," in Wrench, J. and Solomos, J. (eds.) Racism and Migration in Western Europe, Oxford: Berg Publishers, pp. 17-34.

Castells, M. (1996) The Rise of the Network Society, Oxford: Blackwell.

Christou, A. (2001) "The Struggle, Success, and National Consciousness of the Greek Diaspora in America," in Koski, L. and Pajala, K. (eds.) American Studies at the Millennium: Ethnicity, Culture \& Literature, Finland: University of Turku, pp. 125135 .

(2002) "Greek American Return Migration: Constructions of Identity and Reconstructions of Place," Studi Emigrazione, no. 145, pp. 201-229.

. (2003a) Narratives of Place, Culture and Identity: Second-Generation GreekAmericans Return 'Home', Brighton, University of Sussex, DPhil thesis.

- (2003b) "Persisting Identities: Locating the Self and Theorizing the Nation," Berkeley Journal of Sociology: A Critical Review, Special issue: Nationalisms: Negotiating Communities, Boundaries, and Identities, vol. 47, pp. 115-134.

- (2003c) “Migrating Gender: Feminist Geographies in Women's Biographies of Return Migration," Michigan Feminist Studies, Special issue: Gender and Globalism, Issue Number 17, pp. 71-103.

Cloke, P. et al. (1991) Approaching Human Geography: An Introduction to Contemporary Theoretical Debates, London: Paul Chapman Publishing.

Constantinou, S.T. (1996) "Greek American Networks," in Prevelakis, G. (ed.) The Networks of Diasporas, Nicosia, Cyprus: KYKEM (Cyprus Research Center), pp. 305-321.

- (2002) "Profiles of Greek-Americans," in Berry, K.A. and Henderson, M.L. (eds.) Geographical Identities of Ethnic America: Race, Space, and Place, Reno \& Las Vegas: University of Nevada Press, pp. 92-115.

Cordero-Guzman, H. et al. (eds.) (2001) Migration, Transnationalization, and Race in a Changing New York, Philadelphia: Temple University Press.

Domingues, J.M. (2000) Social Creativity, Collective Subjectivity and Contemporary Modernity, London: MacMillan.

Dwyer, C. and Limb, M. (2001) "Introduction: Doing Qualitative Research in Geography," in Limb, M. and Dwyer, C. (eds.) Qualitative Methodologies for Geographers: Issues and Debates, London: Arnold, pp. 1-20.

Elias, N. (1978) The History of Manners, Oxford: Blackwell. 
Ellis, C. and Bochner, A.P. (2000) "Autoethnography, Personal Narrative, Reflexivity: Researcher as Subject," in Denzin, N.K. and Lincoln, Y.S. (eds.) Handbook of Qualitative Research. Second Edition. Thousand Oaks, California: Sage Publications.

Elliot, B. (1997) "Migration, Mobility, and Social Process: Scottish Migrants in Canada," in Bertaux, D. and Thompson, P. (eds.) Pathways to Social Class: A Qualitative Approach to Social Mobility, Oxford: Clarendon Press, pp. 198-229.

Faist, T. (1997) "The Crucial Meso-Level," in Hammar, T. et al. (eds.) International Migration, Immobility and Development: Multidisciplinary Perspectives, New York: Berg Publishers, pp. 187-217.

-. (2000) The Volume and Dynamics of International Migration and Transnational Social Spaces. Oxford: Clarendon Press.

Foner, N. (1998) "Towards a Comparative Perspective on Caribbean Migration," in Chamberlain, M. (ed.) Caribbean Migration: Globalised Identities, New York: Routledge, pp. 47-60.

Gans, H.J. (1992) "Second-Generation Decline: Scenarios for the Economic and Ethnic Futures of the Post-1965 American Immigrants," Ethnic and Racial Studies, vol. 15, no. 2, pp.173-92.

Gergen, M.M. and Gergen, K.J. (2000) "Qualitative Inquiry: Tensions and Transformations," in Denzin, N.K. and Lincoln, Y.S. (eds.) Handbook of Qualitative Research. Second Edition. Thousand Oaks, California: Sage Publications, pp. 10251046.

Giddens, A. (1984) The Constitution of Society, Cambridge: Polity.

Glick Schiller, N. et al. (1992) Towards a Transnational Perspective on Migration, New York: New York Academy of Sciences.

Goffman, E. (1969) Strategic Interaction, Philadelphia: University of Pennsylvania Press.

Hammersley, M. and Atkinson, P. (1983) Ethnography: Principles in Practice. London: Tavistock.

Hannerz, U. (1996) Transnational Connections: Culture, People, Places, London: Routledge.

Karpathakis, A. (1994) "Whose Church Is It Anyway? Greek Immigrants of Astoria, New York, and Their Church," Journal of the Hellenic Diaspora, Special Issue: Rethinking Greek America, vol. 21, no. 1, pp. 97-122.

Latour, B. (1987) Science in Action, Cambridge, MA: Harvard University Press.

- (1988) "The Prince for Machines as well as for Machinations," in Elliot, B. (ed.) Technology and Social Process, Edinburgh: Edinburgh University Press, pp. 20-43.

Law, J. (1988) "The Anatomy of a Socio-technical Struggle: The Design of the TSR2," in Elliot, B. (ed.) Technology and Social Process, Edinburgh: Edinburgh University Press, pp. 44-69.

—_. (1991) "Introduction," in Law, J. (ed.) A Sociology of Monsters: Essays on Power, Technology and Domination, London: Routledge, pp. 1-23.

Levitt, P. et al. (eds.) (2002) The Changing Face of Home: The Transnational Lives of the Second Generation, New York: Russell Sage Foundation.

Light, I. and Gold, S. (2000) Ethnic Economies, San Diego: Academic Press.

Maffesoli, M. (1996) The Time of the Tribes, London: Sage (trans. Rob Shields, originally published in French, Les Temps des Tribus, 1988, Paris: Meridiens Klincksieck).

Marger, M.N. (2001) “The Use of Social and Human Capital among Canadian Business Immigrants," Journal of Ethnic and Migration Studies, vol. 27, no. 3, pp. 439-453. 
Nelson, C. et al. (1992) "Cultural Studies: An Introduction," in Grossberg, L. et al. (eds.) Cultural Studies, New York: Routledge, pp.1-16.

Massey, D. et al. (1998) Worlds in Motion: Understanding International Migration at the End of the Millennium. Oxford: Clarendon Press.

Murphy, P. (1998) "The Seven Pillars of Nationalism," Diaspora, vol. 7, no. 3, pp. 369415.

Nelson, L. (1999) "Bodies (and Spaces) do Matter: The Limits of Performativity," Gender, Place and Culture, vol. 6, no. 4, pp. 331-353.

Portes, A. (1995) "Economic Sociology and the Sociology of Immigration: A Conceptual Overview," in Portes, A. (ed.) The Economic Sociology of Immigration: Essays on Networks, Ethnicity and Entrepreneurship, New York: Russell Sage Foundation, pp. 1-41.

Pries, L. (ed.) (1999) Migration and Transnational Social Spaces, Aldershot: Ashgate.

Pickering, M. (1997) History, Experience and Cultural Studies, London: Macmillan.

Pred, A. (1989) "The Locally Spoken Word and Local Struggles," Environment and Planning D: Society and Space, vol. 7, pp. 211-33.

Radcliffe, S.A. (1993) “Women's Place/El Lugar De Mujeres: Latin America and the Politics of Gender Identity," in Keith, M. and Pile, S., (eds.) Place and the Politics of Identity, London: Routledge, pp. 102-116.

Robins, K. (1995) "Cyberspace and the World We Live In," in Featherstone and Burrows (eds.) Cyberspace/Cyberbodies/Cyberpunk, London: Sage.

Rumbaut, R. and Portes, A. (eds.) (2001) Ethnicities: Children of Immigrants in America. Berkeley and New York: University of California Press and Russell Sage Foundation.

Thompson, E.P. (1978) The Poverty of Theory, London: Merlin Press.

Yang, M. M.C. (1972) "How A Chinese Village was Written," in Kimball, S.T. and Watson, J.B. (eds.), Crossing Cultural Boundaries: The Anthropological Experience, San Francisco: Chandler, pp. 63-73. 